\title{
$\beta$-SIALON の酸化銅による溶損侵食に及ぼす粒界相の影響
}

\author{
久留島豊一・石㟝幸三*・濱崎豊弘 $* *$ \\ (株) INAX 中央研究所, 479 常滑市久米字鎗場 36 \\ *長岡技術科学大学機械系材料設計大講座, 940-21 長岡市上富岡町 1603-1 \\ **長岡技術科学大学大学院材料工学専攻, 940-21 長岡市上富岡町 1603-1
}

\author{
Effects of Grain Boundary Phases on the Corrosion of $\boldsymbol{\beta}$-SIALON in Molten Copper Oxide \\ Toyokazu KURUSHIMA, Kozo ISHIZAKI* and Toyohiro HAMASAKI** \\ Central Research Laboratory, INAX Corporation, 36, Kume-aza-Yariba, Tokoname-shi, Aichi 479 \\ *Department of Materials Science and Engineering, School of Mechanical Engineering, \\ Nagaoka University of Technology, 1603-1, Kamitomioka-cho, Nagaoka-shi, 940-21 \\ **Materials Science Course, Graduate School, Nagaoka University of Technology, 1603-1, Kamitomioka-cho, Nagaoka-shi, 940-21
}

[Received May 22, 1992; Accepted August 21, 1992]

\begin{abstract}
The present investigation reveals that grain boundaries of $\beta$-SIALON are corroded selectively by molten copper oxide. $\beta$-SIALON ceramics become more vulnerable as the amount of grain boundary phase, mainly glass, increases. High density $\beta$-SIALON ceramics (fraction to the theoretical density from 0.9 to 1 ) were heated with $\mathrm{CuO}$ powder at $1200{ }^{\circ} \mathrm{C}$ for $1 \mathrm{~h}$ in air. The HIPped sample which had the highest density was corroded most severely, in contradiction to the general relationship between density and corrosion of refractories. Cryogenic specific heat measurements showed that the HIPped sample contained the largest amount of grain boundary phases. Among the normally sintered samples, one with larger amount of grain boundary phases was corroded most severely. The difference of the amount of grain boundary phases may have been attributed to the thermal treatment conditions, especially to the cooling rate and the highest temperature attained. The corrosion behavior of $\beta$-SIALON ceramics in molten copper oxide coincided well with the results of SEM observations and the data of phase diagrams. Also, the cryogenic specific heat is a sensitive property, with which slight differences of the amount of grain boundary phases can be detected. These small differences can not be distinguished by means of SEM observations or XRD analysis.
\end{abstract}

Key-words : SIALON, Corrosion, Copper oxide, Grain boundary, Glassy phase, HIP, Density, Cryogenic specific heat

\section{1. 緒 言}

SIALON は溶融金属との濡れ性が悪く，比較的熱衝撃 に強く, 高温強度も大きく, $\mathrm{Si}_{3} \mathrm{~N}_{4}$ よりも高温酸化に強い ことから，新しい高性能耐火物として期待されている1).

しかしながら，溶融金属に伴う高温ガス，スラグによる酸 化反応と溶損侵食が問題となり, 溶融温度の低いアルミ二 ウム以外では実用化されていない。鉄鋼分野では溶融鋼中 での SIALON や $\mathrm{Si}_{3} \mathrm{~N}_{4}$ の寿命を調べるために，回転侵食 法を用いた実験が行われており， $\mathrm{Si}_{3} \mathrm{~N}_{4}$ よりも SIALON の方が高寿命であり，その理由は表面にアルミナ被膜を形 成するからであると結論づけている2)〜4).
ところで著者らは，窒化物セラミックスと銅，酸化銅の 反応を調べ，溶融銅合金中での窒化物セラミックスの溶損 侵食が溶融酸化銅によって起こり, 溶融銅合金の場合は, SIALON より $\mathrm{Si}_{3} \mathrm{~N}_{4}$ の方が高寿命であると予測した ${ }^{5)}$. 原 藤らは， $\beta$-SIALON がアルミニウムには溶損侵食されな いが銅には侵食されることを指摘し，その原因は $\beta$-SIALON の表面酸化物と溶融金属酸化物の反応で説明できる としている6).

著者らは，溶融鋼には溶損侵食されにくいSIALON が 溶融銅合金に溶損侵食されやすい原因の一つは確かに酸化 銅であるが，一方 SIALON セラミックスの側の粒界相の 影響があると考えている. セラミックスの粒界相を評価す る方法として, 渡利らは $\mathrm{Si}_{3} \mathrm{~N}_{4}$ 焼結体を用い, 低温比熱の 温度依存性を比較することを提案し7), 確かめられた8). また，濱崎らは低温比熱測定装置を作製し， $\mathrm{Si}_{3} \mathrm{~N}_{4}$ 焼結体 の粒界ガラス相の定量化を行った $\left.{ }^{9)}, 10\right)$. 本研究では, 濱崎 らが作製した低温比熱測定装置9),10)により $\beta$-SIALON の 粒界相量の比較を行い, 焼成温度, 密度と粒界相量の関 係, 及びこれらと溶損侵食量の関係について実験と考察を 行った．その結果いくつかの新知見を得たので報告する.

\section{2. 実験方法}

\subsection{SIALON セラミックスの作製}

市販の $\beta$-SIALON $\left(\mathrm{Si}_{4} \mathrm{Al}_{2} \mathrm{O}_{2} \mathrm{~N}_{6}\right)$ 粉末 $99 \mathrm{wt} \%$ (平均粒 径0.6 $\mu \mathrm{m}$ ）に $\mathrm{Y}_{2} \mathrm{O}_{3}$ 粉末 $1 \mathrm{wt} \%$ （平均粒径 $3 \mu \mathrm{m}$ ）を添加 し，これらをアルミナボール，エタノールとともにナイロ ンポットに入れ，24時間の湿式混合を行った。乾燥は ホットプレート上で急速に行い， $0.5 \mathrm{~mm}$ のふるいを通し て造粒した，造粒後は調合物を50gずつ秤量し， 型に詰めて, 単軸プレス装置を用い $20 \mathrm{MPa}$ でプレス成形 し, その後, 成形体をゴムチューブに真空脱気して詰め, $100 \mathrm{MPa}$ で CIP 処理した.

焼成は小型雲囲気炉を用い, 窒素雾囲気中で, 表 1 に示 す $1600^{\circ} \mathrm{C}$ から $1750^{\circ} \mathrm{C}$ 温度で行った（表 1 の No. 1〜5). 昇温は室温加 $51600^{\circ} \mathrm{C}$ を゙ $10^{\circ} \mathrm{C} / \mathrm{min}, 1600^{\circ} \mathrm{C}$ か $1750^{\circ} \mathrm{C}$ をでを $3^{\circ} \mathrm{C} / \mathrm{min}$ で行い，保持時間は 2 時間とした. 
Table 1. Sintering conditions. Sample No. 6 was HIP treated after normal sintering.

\begin{tabular}{c|cc:|ccc}
\hline \multirow{2}{*}{ Sample } & \multicolumn{2}{|c|}{ Sintering } & \multicolumn{2}{c}{ HIP } & Treatment \\
& Temp. & Time & Temp. Press. Time \\
No. & $/$ q & $/ \mathrm{hr}$ & $/$ T $/ \mathrm{MPa}$ & $/ \mathrm{hr}$ \\
\hline 1 & 1600 & 2 & - & - & - \\
2 & 1650 & 2 & - & - & - \\
3 & 1680 & 2 & - & - & - \\
4 & 1700 & 2 & - & - & - \\
5 & 1750 & 2 & - & - & - \\
6 & 1750 & 2 & 1600 & 100 & 1 \\
\hline
\end{tabular}

降温は最高温度から $1000^{\circ} \mathrm{C}$ を゙ $10^{\circ} \mathrm{C} / \mathrm{min}, 1000^{\circ} \mathrm{C} ら$ 室温までを自然冷却により約 6 時間で行った.

$1750^{\circ} \mathrm{C}$ で焼成した試料の一部は，100 MPaの窒素ガス 中でカプセルフリーHIP 処理を行った（表 1 のNo. 6). その際の昇温は $10^{\circ} \mathrm{C} / \mathrm{min}$, 保持時間は 1 時間で, 降温は 自然冷却により約 1 時間で室温まで冷却した。

それぞれの焼成体は，ダイヤモンドカッターで $10 \times 10 \times 7 \mathrm{~mm}$ の直方体に切断加工して供試体とした.

\section{2 溶損侵食試験とその評価}

$\beta$-SIALON 供試体の密度をアルキメデス法により測定 した後, アルミナるつぼ中に試料 1 個と $\mathrm{CuO}$ 粉末 $10 \mathrm{~g}$ を 入れ, 大気中 $1200^{\circ} \mathrm{C} て ゙ 1$ 時間加熱することにより, 溶損 侵食試験を行った. 評価は溶損による 3 辺の長さの平均 減量と重量減量を測定することにより行った.

\section{3 低温比熱測定}

濱崎らの開発した低温比熱測定装置9),10)を用い，表 1 の No. 1, 5, 6 の 3 試料について, $10 \mathrm{~K}$ から $40 \mathrm{~K}$ の温度で比 熱を測定し，その結果を比較することで粒界相の比較評価 を行った。

\section{4 走査型電子顕微鏡 (SEM) 観察及び XRD 分析}

溶損侵食試験前後に, 試料の SEM 観察及び XRD 分析 を行い，溶損侵食試験結果や低温比熱測定結果との比較を 行った.

\section{3. 結 果}

$\beta$-SIALON の焼成温度と理論密度比, $\rho$ (密度を理論密 度で割った值）の関係を図 1 に示す。 $\beta$-SIALON の理論 密度比は, $1680^{\circ} \mathrm{C}$ で 0.99 以上に達し, $1680^{\circ} \mathrm{C}$ か $1750^{\circ} \mathrm{C}$ の間は焼成温度を上げてもほとんど増加しなかった。 $1750^{\circ} \mathrm{C}$ で焼成した試料を更に $1600^{\circ} \mathrm{C} て ゙ \mathrm{HIP}$ 処理すると, 理論密度比 1 に達した.

図 2 には $\beta$-SIALON の理論密度比と溶損侵食試験によ る重量減量及び寸法減量の関係を示した．重量減量は密度 の違いを考慮した比で，寸法減量は 3 辺の長さの違いを 考慮して実寸法で示したが，両者の傾向はよく似た結果と なった。いずれの試料も溶損侵食が著しいが，HIP 処理 した試料が特に激しく侵食されている. また常圧焼成の試 料に抢いては，わずかではあるが理論密度比が高いほど侵

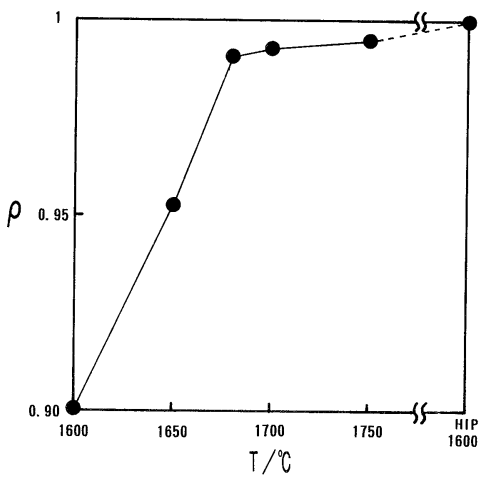

Fig. 1. Fraction to the theoretical density, $\rho$ as a function of sintering temperature, $T$. The HIPped sample was normally sintered at $1750^{\circ} \mathrm{C}$ first, and capsule-free-HIPped at $1600^{\circ} \mathrm{C}$ under 100 $\mathrm{MPa}$ of nitrogen. $\rho$ of $\beta$-SIALON reached above 0.99 at $1680^{\circ} \mathrm{C}$, hardly increased at the sintering temperatures between $1680^{\circ} \mathrm{C}$ and $1750^{\circ} \mathrm{C}$, and fully densified by HIPping.

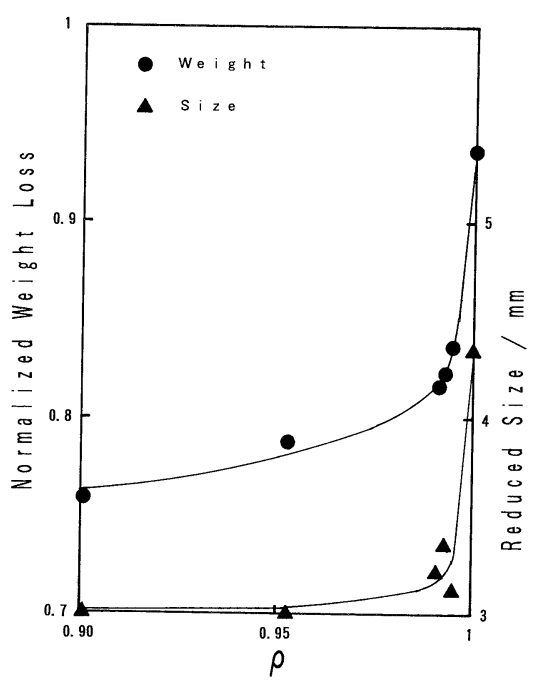

Fig. 2. The reduction of sample in weight ratio and size by corrosion as a function of fraction to the theoretical density, $\rho$. The circles and triangles indicate the corroded quantities in weight ratio and size respectively. Both of them indicate similar tendency. All samples were remarkably corroded by copper oxide at $1200^{\circ} \mathrm{C}$ in air. A sample with the higher $\rho$ corroded more than lower ones. The HIPped sample was remarkably more corroded than non HIPped ones.

食されやすい傾向を示している.

図 3 には表 1 中の $\beta$-SIALON 試料 No. 1, 5, 6 の温度と 比熱の関係を示した. 参考のために, 渡利らが $\mathrm{Si}_{3} \mathrm{~N}_{4}$ に関 して求めたデバイ温度 $1100 \mathrm{~K}$ という值7)を用いて計算し た, 温度と比熱の関係も示した. 三つの試料の比熱の違い は，粒界にある相（主としてガラス相やデバイ温度の低い 結晶相)の量の違いによるもので, 理由は考察で述べるが, HIP 処理した試料（No.6）が最も多くの粒界相を含んで いることになる. またNo. 1 と 5 にも明らかな差が確認 できる. 


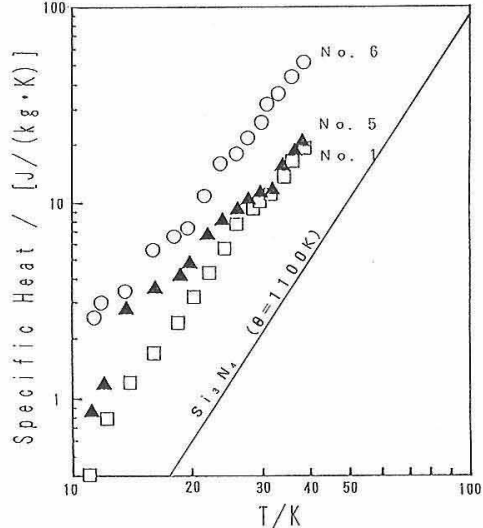

Fig. 3. Specific heat as a function of temperature, $T$. Squares, triangles and circles represent samples No. 1, 5 and 6 respectively as listed in Table 1. For reference, the solid line indicates the calculated specific heat of silicon nitride ceramics which has a Debye temperature of $1100 \mathrm{~K} .{ }^{7}$ ) The difference of the cryogenic specific heats among three samples is due to the difference of quantities of grain boundary phases. Because of the fast cooling rate, the HIPped sample (No. 6) contains more grain boundary glassy phases than the normally sintered samples. The cryogenic specific heat measurement is a sensitive factor for evaluating grain boundary phases of ceramics.

\section{4. 考察}

\section{1 密度と溶損侵食量の関係}

図 2 によると， $\beta$-SIALON の密度が高いほど溶損侵食 量が多いことが分かる．この現象は，耐火物に関して一般 にいわれている「気孔率の増加は耐溶損侵食性を低下させ る」という説11)のまったく逆の傾向を示している．その 原因としては，回転侵食法を用いていないために反応が緩 慢となり，密度差による影響が出にくくなったことも考え られるが，主原因は次の項で説明する粒界相の量の違いに よるものである. Samaddarらは，40CaO- $20 \mathrm{Al}_{2} \mathrm{O}_{3}$ $40 \mathrm{SiO}_{2}$ スラグ中での多結晶 $\mathrm{Al}_{2} \mathrm{O}_{3}$ の溶損侵食が，単結晶 $\mathrm{Al}_{2} \mathrm{O}_{3}$ のそれよりも大きいことを確かめ, 高密度の単相の セラミックスでは溶損侵食が粒界で最も激しいと考えてい

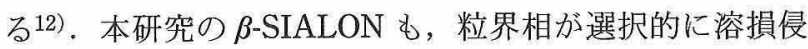
食されたと考えられるが，とにかく焼成温度が低く，密度
の低い $\beta$-SIALON 試料の方が酸化銅による溶損侵食に強 いという事実は新しい発見であり，工業的にも注意を要す る結果でめる.

\section{2 粒界相量と溶損侵食量の関係}

図 3 は $\beta$-SIALON 試料の温度と比熱の関係を示してい るが，比熱の大小は粒界にある低温比熱の高い相（ガラス 相とデバイ温度の低い結晶相)の量に関係している7),8). また，図 3 に扔いて比熱の温度依存性が試料により異な ることから，低温此熱の高い相としては，ガラス相だけで なくガラス相が結晶化した相も含まれていると考えられ る. というのは, 本研究のような $10 \mathrm{~K}$ から $40 \mathrm{~K}$ の温度範 囲に括ける比熱異常は，たとえば $\mathrm{SiO}_{2}$ ガラスと $\alpha$-quartz のように，ガラス相たけでなく結晶相でも見られる13)が， 両者のデバイ理論からの逸脱挙動が異なるからである。な お， $\beta$-SIALON そのもののデバイ温度ははっきりとは分 からないが， $\mathrm{Si}_{3} \mathrm{~N}_{4}(\text { デバイ温度 } 1100 \mathrm{~K})^{8)}$ より低いとして も, 約 $1000 \mathrm{~K}$ はあると考えられる. $\mathrm{SiO}_{2}$ ガラス（デバイ 温度 $500 \mathrm{~K}$ ）は，比熱の異常性が $100 \mathrm{~K}$ 程度より確認され る13)ことから, 今回の $\beta$-SIALON の場合は, $200 \mathrm{~K}$ 程度 よりその異常性が確認でき, $10 \mathrm{~K}$ から $40 \mathrm{~K}$ の温度では, 十分にデバイ理論に従うと考えられる。したがって, 図 3 において，粒界相の量は HIP 処理した試料が最も多く， 常王焼成した試料では焼成盜度が高い方が多く なっている．これらの違いはそれぞれの熱処理条件の違い によると考えられる. HIP 処理した試料の室温末での冷 却時間約 1 時間は，常圧焼成した試料の約 6 時間に比べ て極端に短いため，これによって多くのガラス相が生成さ れたのであろう。また常圧焼成した試料（No.1 と 5) 間 の差は，一つは最高温度が低い万が液相があまりできず，

急冷しても粒界相が少ししかできないこと，もう一つは No. 5 は No. 1 に比べて $1750^{\circ} \mathrm{C} \rightarrow 1600^{\circ} \mathrm{C}$ 間の冷却を余分に 経ているため，この間の急冷で粒界相が多くできたことに より，恐らく両方が関係していると考えられる. 図 4 は試 料 No. 5 の溶損侵食試験前後の SEM 写真で, すべて研磨 した表面の状態を示している，(a)と(b)を比べると，酸 化銅による溶損侵食が燒結体内部まで進み，多数の欠陥部 分が生じていることが分かる. (c) は (b)を桩大した写真
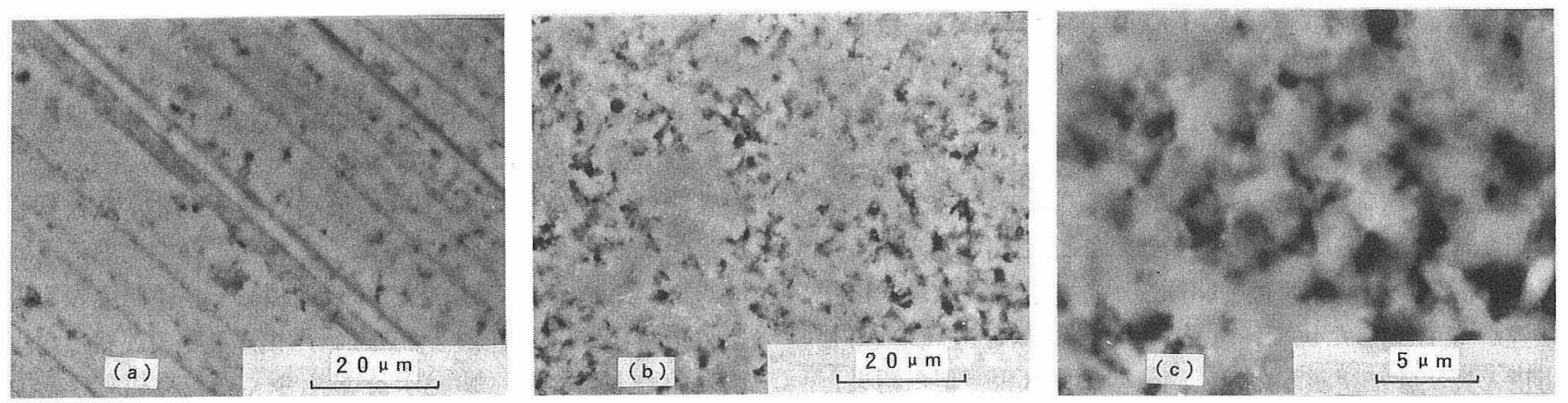

Fig. 4. SEM micrographs of polished surfaces of sample No. 5 (a) before and (b) after the corrosion test. The voids on the surface became larger by the corrosion test. The scale markers indicate $20 \mu \mathrm{m}$.

(c) Magnified SEM micrograph of (b). The pores (black areas) are located around the grains (white portions). The grain boundary phases are corroded by copper oxide selectively. The scale marker indicates $5 \mu \mathrm{m}$. 
(a)

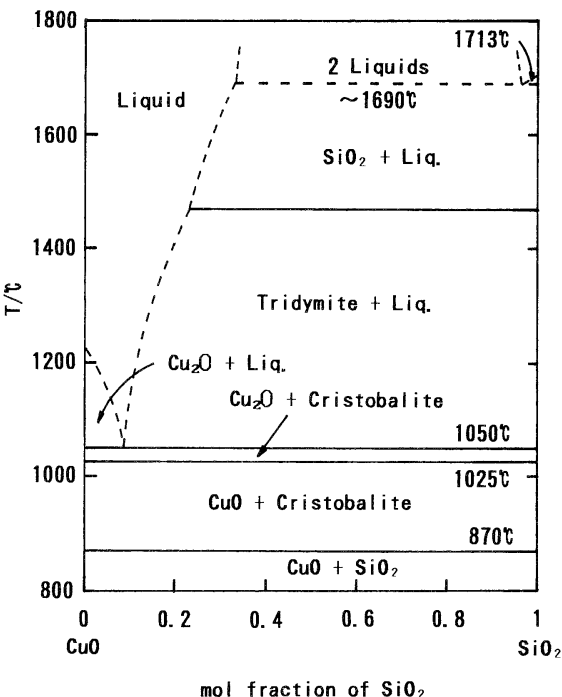

(b)

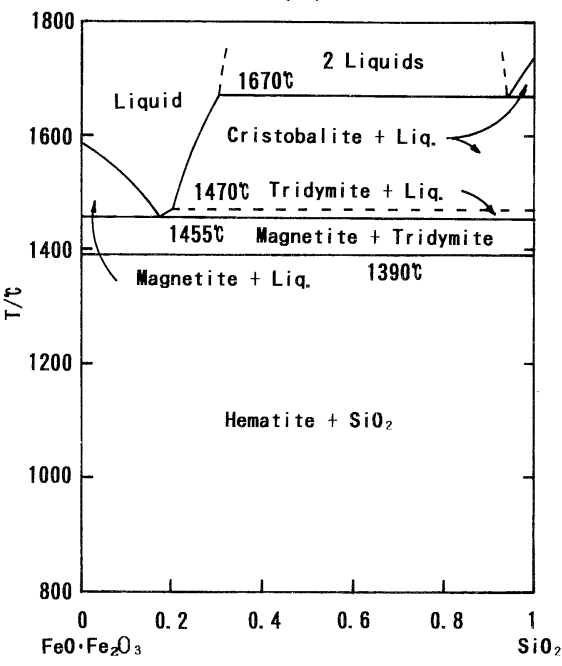

mol fraction of $\mathrm{SiO}_{2}$

Fig. 5. Phase diagrams of (a) $\mathrm{CuO}-\mathrm{SiO}_{2}$ and (b) $\mathrm{FeO} \cdot \mathrm{Fe}_{2} \mathrm{O}_{3}-\mathrm{SiO}_{2}$ systems drawn using data from Ust'yantsev, Sudakova and Bessonov (1966), ${ }^{14)}$ and Phillips and Muan (1959) ${ }^{15)}$ respectively. At $1200^{\circ} \mathrm{C}$, the $\mathrm{SiO}_{2}$ component has liquid phase, when it is in contact with copper oxide, but does not with iron oxide.

であるが，これによると欠陷部分（黒い部分）は結晶粒（白 い部分）の周りにそって生じていることが分かる。つまり 溶損侵食は粒界を選択的に伝って進んでいるのである。こ のことは，先にも述べた Samaddar らの $40 \mathrm{CaO}-20 \mathrm{Al}_{2} \mathrm{O}_{3}$ $40 \mathrm{SiO}_{2}$ スラグ中での多結晶 $\mathrm{Al}_{2} \mathrm{O}_{3}$ の結果 ${ }^{12)}$ と一致してい る.

以上のことから，粒界にガラス相を多く含む $\beta$-SIALON 試料は，酸化銅による溶損侵食を受けやすく，粒界 のガラス相の量は焼成温度が高く，冷却速度が速いほど多 くなることが言え, 改めて本研究の $\beta$-SIALON は「気孔 率の増加は耐溶損侵食性を低下させる」という一般論には 当てはまらない理由が確認された。

ところで，本研究ではすべての試料について SEM 観察 とXRD分析を行ったが, 原料粉末に最初から $\beta$ SIALONを用いたこともあり，これらによっては粒界相 量や侵食挙動の違いを見いだすことができなかった．とこ ろが，低温比熱測定においては明らかな粒界相量の違いが 見いだせた。低温比熱はセラミックスの粒界相を評価する ための，非常に敏感で有益な要因であり，これによってあ らかじめ非破壊で $\beta$-SIALON の酸化銅による耐溶損侵食 性を評価することもできる.

\section{3 酸化銅による溶損侵食原因}

図 5 は Ust'yantsev $5 \quad(1966)^{14)}$ と Phillips と Muan (1959) 15) の報告を用いて描いた $\mathrm{CuO}-\mathrm{SiO}_{2}$ 系と $\mathrm{FeO}$. $\mathrm{Fe}_{2} \mathrm{O}_{3}-\mathrm{SiO}_{2}$ 系の状態図である。溶損侵食試験を行った $1200^{\circ} \mathrm{C}$ では， $\mathrm{SiO}_{2}$ 成分は常に酸化銅と接触していると液 相になるが，酸化鉄と接触しても液相にはならない。

一方，図 4 に扔いて酸化銅が $\beta$-SIALON の粒界相を選 択的に溶損侵食することを示した． $\beta$-SIALONの粒界に は当然ケイ酸質のガラス相ないし，それから結晶化した相 が生成されていると考えられる。

状態図と SEM 写真の内容は， $\beta$-SIALON が溶融鋼中で
溶損侵食されにくいのに，溶融銅合金中で激しく溶損侵食 される現象によく一致しており，その原因はスラグの主成 分である酸化銅が粒界にあるケイ酸質のガラス相を液化す るためであると言える。したがって，耐溶損侵食性を増加 させるには粒界にガラス相を生成させないことが重要とな る.

\section{5. 結 論}

$\beta$-SIALON $\left(\mathrm{Si}_{4} \mathrm{Al}_{2} \mathrm{O}_{2} \mathrm{~N}_{6}\right)$ の酸化銅による溶損侵食試験 を大気中 $1200^{\circ} \mathrm{C} て ゙ 1$ 時間行うこと，及び $10 \mathrm{~K}$ から $40 \mathrm{~K}$ の温度で低温比熱を測定して粒界の結晶度の低い相量を比 較することにより次の結論を得た。

（1） 本研究の $\beta$-SIALON は，耐火物に関して従来から 言われている，「気孔率の増加は耐溶損侵食性を低下させ る」という説には当てはまらない.

（2） $\beta$-SIALON の酸化銅による溶損侵食量は，粒界の 主としてガラス相の量に大きく影響される。したがって冷 却速度の速かった HIP 処理試料は，冷却速度の遅かった 常圧焼成試料に比べて密度が高いにもかかわらず，溶損侵 食量が著しく多かった．また常圧焼成のみの試料において も，焼成温度が高く高密度の試料の方が粒界相を多く含 み，よって溶損侵食量も多かった。

（3） $\beta$-SIALON は溶融鋼及びそのスラグには溶損侵食 されにくいことが知られているが，溶融酸化銅には激しく 溶損侵食される。これは，粒界のケイ酸質ガラス相，又は それが結晶化した相が酸化銅と反応し，溶融することが原 因であることが判明した。そして，このことは状態図から 導かれる二酸化ケイ素と酸化銅の反応々一致する.

（4）低温比熱測定による粒界の結晶度の低い相量の比 較は非常に敏感にでき，SEM 観察やXRD で比較不可能 な差でも比較することができる。なたこれにより，あらか じめ非破壊で酸化銅による耐溶損侵食性を評価することも 
できる。

（5）粒界ガラス相と考えられる部分が選択的に溶損侵 食されていることが，SEM 観察により確認できた.

\section{文献}

1）菅野 武, “サイアロンセラミックスの使い勝手”，日経二 ューマテリアル，12，日経 BP (1987) pp. 24-35.

2) 前田榮三, 新谷宏隆, 川上辰男, 岸 高寿, 窯協, 88, 523-31 (1980)

3）寺尾公一，鈴木隆夫，荒堀忠久，窐協，94，111-15 (1986).

4) M. B. Trigg, D. B. Ellson and W. Sinclair, Br. Ceram. Trans. J., 87, 153-57 (1988).

5）久留島豊一, 石㠃幸三, J. Ceram. Soc. Japan, 100, 955-59 (1992).

6）原藤和敬，古島清史，森永健次，日本鋳物協会全国講演大 会講演概要集, 111 (1987) p. 56.

7）渡利広司, 関喜幸, 石㠃幸三, セラミックス論文誌,
97, 174-81 (1989).

8) K. Watari, K. Ishizaki and K. Mori, J. Am. Ceram. Soc., 74, 244-46 (1991).

9）濱崎豊弘, 石嵭幸三, 森 克徳, 日本セラミックス協会第 4 回秋季シンポジウム講演予稿集 (1991) p. 166.

10) T. Hamasaki and K. Ishizaki, Proc. of the Int. Workshop on Fine Ceram., "Materials Processing and Design Through Better Control of Grain Boundary Properties: Emphasizing Fine Ceramics", Ed. by K. Ishizaki, K. Niihara, M. Isotani and R. Ford, Elsevier Sci. Pub., London (1992) in press.

11）例えば，吉木文平，“耐火物工学”，技報堂出版（1962）p. 144 .

12) B. N. Samaddar, W. D. Kingery and A. R. Cooper, Jr., J. Am. Ceram. Soc., 47, 249-54 (1964).

13) R. C. Zeller and R. O. Pohl, "Amorphous Solids", Ed. by W. A. Phillips, Springer Verlag, Berlin (1981) pp. 27-52.

14) V. M. Ust'yantsev, L. P. Sudakova and A. F. Bessonov, $Z h$. Neorgan. Khim., 11, 1177 (1966).

15) B. Phillips and A. Muan, J. Am. Ceram. Soc., 42, 415 (1959). 